\title{
Nonisothermal Bulk Crystallization and Subsequent Melting Behavior of Syndiotactic Polypropylenes: Crystallization from the Melt State
}

\author{
PITT SUPAPHOL \\ The Petroleum and Petrochemical College, Chulalongkorn University, Soi Chulalongkorn 12, Phyathai Road, Pathumwan, \\ Bangkok 10330, Thailand
}

Received 13 August 1999; accepted 15 December 1999

\begin{abstract}
Various macrokinetic models, namely, the Avrami, the Tobin, and the Ozawa models, were applied to describe the crystallization process of syndiotactic polypropylene (s-PP) under nonisothermal conditions. Both Avrami and Tobin models were shown to provide a fair description of the experimental data. The Avrami exponent $n_{a}$ was found to range from 2.4 to 5.3 , while the Tobin exponent $n_{t}$ was found to range from 3.1 to 6.7. The Ozawa model was found to describe the nonisothermal crystallization kinetics of s-PP very well. The Ziabicki's kinetic crystallizability, suggesting the crystallization ability of polymers from the melt when cooled at a unit cooling rate, was also evaluated and was found to range from 0.93 to $1.40^{\circ} \mathrm{C} \mathrm{s}^{-1}$. The energy barrier for nonisothermal crystallization, based on the Augis-Bennett method, was found to range from -78.6 to $-108.1 \mathrm{~kJ} \mathrm{~mol}^{-1}$. (c) 2000 John Wiley \& Sons, Inc. J Appl Polym Sci 78: 338-354, 2000
\end{abstract}

Key words: syndiotactic polypropylene; nonisothermal crystallization; melting behavior; Avrami analysis; Tobin analysis; Ozawa analysis; kinetic crystallizability; Augis-Bennett method; Kissinger method; Takhor method

\section{INTRODUCTION}

The syndiotactic form of polypropylene (s-PP) was first synthesized in the early 1960 s by Natta et al. ${ }^{1,2}$ based on Ziegler-Natta catalysis, but the resulting polymer contained too high a level of regio-irregular defects (e.g., head-to-head/tail-totail-type defects) despite a fair level of syndiotactic content. A much improved s-PP was successfully synthesized in 1988 by Ewen et al. ${ }^{3}$ who reported that highly stereoregular and regioregular s-PP can be polymerized using a novel metallocene catalysis. The new catalyst systems have made it possible to produce s-PP with much im-

\footnotetext{
Correspondence to: P. Supaphol (ps@sunsv1.ppc.chula. ac.th).

Journal of Applied Polymer Science, Vol. 78, 338-354 (2000)

(ㄷ) 2000 John Wiley \& Sons, Inc.
}

proved purity and yields, which led to renewed interest in both scientific researches ${ }^{4}$ and industrial applications. ${ }^{5-7}$

Studies of the kinetics of polymer crystallization are of great importance in polymer processing, due to the fact that the resulting physical properties are strongly dependent on the morphology formed and the extent of crystallization during processing. It is therefore very important to understand the processing-structure-property interrelationships of the studied materials, which in this case is s-PP. Investigations related to the chain conformation, crystal structure, morphology, and phase transitions in s-PP have been reported extensively in recent years. These studies up to 1994 were reviewed and discussed in a publication by Rodriguez-Arnold et al. ${ }^{4}$ Studies which have been carried out on the subject of 
Table I Characterization Data of As-Received s-PP Samples

\begin{tabular}{|c|c|c|c|c|c|c|c|c|c|}
\hline Sample & $\begin{array}{l}\text { Intrinsic } \\
\text { Viscosity } \\
\left(\mathrm{dL} \mathrm{g}^{-1}\right)\end{array}$ & $M_{n}$ & $M_{w}$ & $M_{z}$ & $M_{w} / M_{n}$ & $\begin{array}{l}\text { Racemic } \\
\text { Pentads } \\
(\% \text { rrrr })\end{array}$ & $\begin{array}{c}\text { Racemic } \\
\text { Triads } \\
(\% r r)\end{array}$ & $\begin{array}{c}\text { Racemic } \\
\text { Dyads } \\
(\% r)\end{array}$ & $\begin{array}{c}\text { Ethylene } \\
\text { Content } \\
\text { (\% by wt) }\end{array}$ \\
\hline s-PP\#1 & 1.61 & 76,200 & 165,000 & 290,000 & 2.15 & 77.10 & 87.31 & 91.42 & 1.3 \\
\hline s-PP\#2 & 1.80 & 52,300 & 195,000 & 450,000 & 3.73 & 74.55 & 83.09 & 87.36 & 0.6 \\
\hline s-PP\#3 & 1.32 & 37,300 & 133,000 & 308,000 & 3.55 & 74.61 & 83.73 & 88.29 & 0.5 \\
\hline s-PP\#4 & 1.61 & 81,300 & 171,000 & 294,000 & 2.10 & 74.63 & 84.37 & 89.24 & 0.3 \\
\hline s-PP\#5 & 1.52 & 47,000 & 165,000 & 406,000 & 3.51 & 75.28 & 85.09 & 90.00 & 0.2 \\
\hline
\end{tabular}

isothermal crystallization kinetics of s-PP include isothermal Avrami crystallization kinetics ${ }^{8-11}$ and the isothermal kinetics of the linear growth rates..$^{8,10,12-14}$ Importantly, few publications ${ }^{8,15}$ have been dedicated to the studies of nonisothermal crystallization behavior of s-PP, and to the best of our knowledge, only one publication ${ }^{16}$ has been dedicated to the subject of nonisothermal crystallization kinetics of s-PP thus far.

In this article, a differential scanning calorimeter (DSC) was used to study nonisothermal crystallization and subsequent melting behavior of s-PP. Different theoretical approaches ${ }^{17-22}$ were used to describe the kinetics of nonisothermal crystallization. The activation energy describing the overall crystallization process under nonisothermal condition was also calculated based on various theoretical propositions..$^{23-25}$

\section{EXPERIMENTAL}

\section{Materials}

The s-PP samples used in this study were supplied in pellet form by Fina Oil and Chemical Co. (La Porte, TX). Molecular characterization data, which were kindly measured by Dr. Roger A. Phillips and his coworkers at Montell USA, Inc., in Elkton, Maryland, are summarized in Table I. It is worth noting that s-PP\#2, s-PP\#3, and s-PP\#5 exhibit a bimodal molecular weight distribution, which results in an unusually high degree of polydispersity.

\section{Sample Preparation and Experimental Methods}

Sliced pellets were melt-pressed between a pair of Kapton films, which, in turn, were sandwiched between a pair of thick metal plates, in a Wabash compression-molding machine preset at $190^{\circ} \mathrm{C}$ under a pressure of $67 \mathrm{kpsi}$. After $10 \mathrm{~min}$ holding time, a film of $275 \mu \mathrm{m}$ thickness was taken out and allowed to cool at an ambient condition down to room temperature between the two metal plates. This treatment assumes that the previous thermomechanical history was essentially erased and provides a standard crystalline memory condition for our experiments.

In this article, a Perkin-Elmer Series 7 DSC (DSC-7) was used to study the kinetics of nonisothermal crystallization of s-PP. The DSC-7 equipped with an internal liquid nitrogen cooling unit reliably provided a cooling rate $\phi$ up to $200^{\circ} \mathrm{C}$ $\min ^{-1}$, but reliable measurements can only be conducted when nominal cooling rates are applied (e.g., $\phi \leq 20^{\circ} \mathrm{C} \mathrm{min}^{-1}$ ). Temperature calibration was performed using an indium standard $\left(T_{m}^{0}=\right.$ $156.6^{\circ} \mathrm{C}$ and $\left.\Delta H_{f}^{0}=28.5 \mathrm{~J} \mathrm{~g}^{-1}\right)$. The consistency of the temperature calibration was checked every other run to ensure the reliability of the data obtained. To make certain that the thermal lag between the polymer sample and the DSC sensors is kept to a minimum, each sample holder was loaded with a single disc, weighing around 4.9 $\pm 0.3 \mathrm{mg}$, which was cut from the standard film already prepared. It is noteworthy that each sample was used only once and all the runs were carried out under a nitrogen purge.

The experiment started with heating the sample from $-40^{\circ} \mathrm{C}$ at a scanning rate of $80^{\circ} \mathrm{C} \mathrm{min}{ }^{-1}$ to $190^{\circ} \mathrm{C}$, where it was held for $5 \mathrm{~min}$ before cooling at a desired constant cooling rate $\phi$, ranging from 1 to $20^{\circ} \mathrm{C} \mathrm{min}-1$ (depending particularly on the s-PP sample studied) to $-40^{\circ} \mathrm{C}$. The cooling exotherms were recorded for further analysis based on several kinetics models. The subsequent melting endotherms were also recorded for further observation of the melting behavior. It is worth noting that melting of the sample at $190^{\circ} \mathrm{C}$ for $5 \mathrm{~min}$ is enough to completely melt the crystalline residues which can act as predetermined 


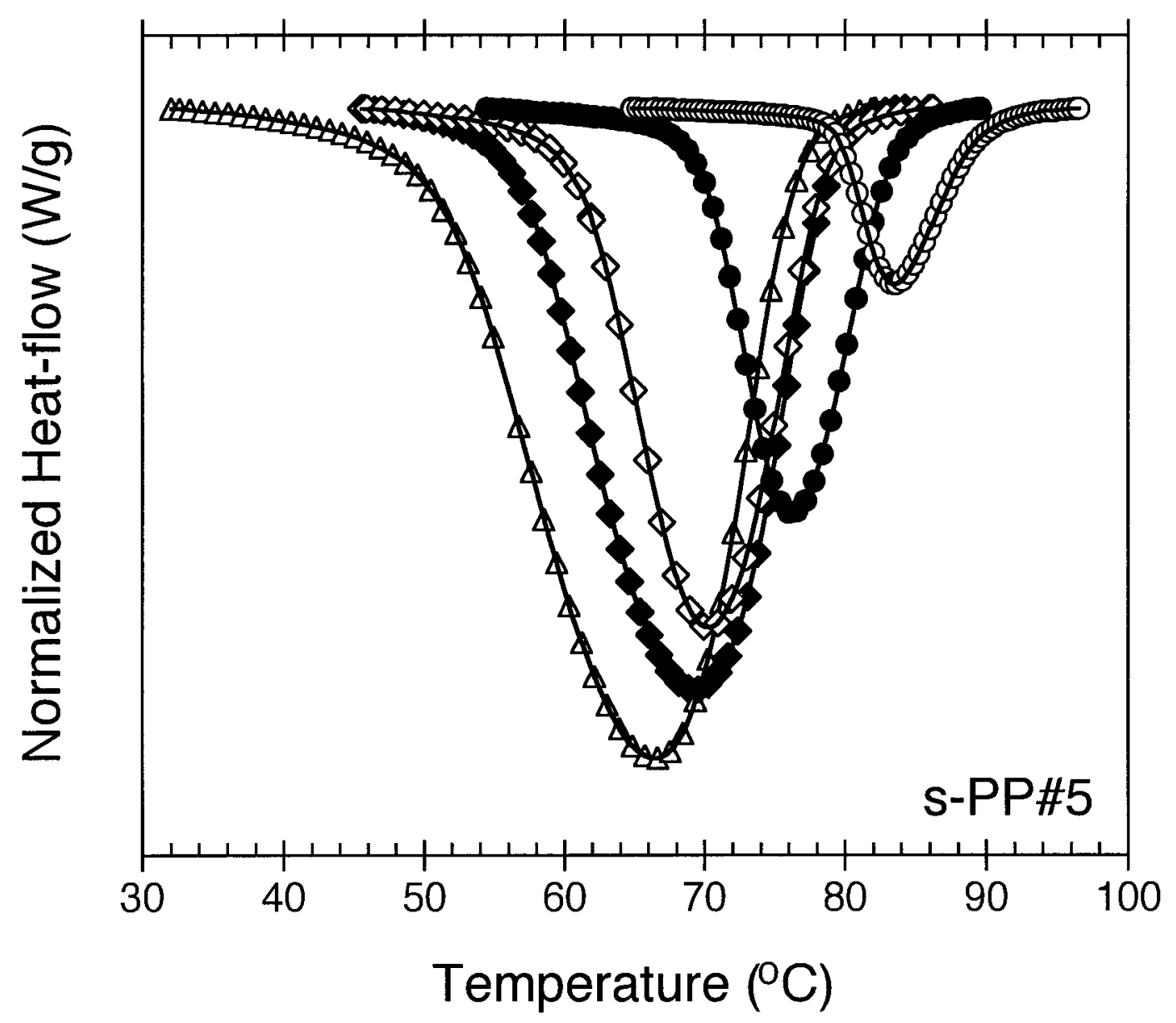

Figure 1 Nonisothermal melt crystallization exotherms of sample s-PP\#5 recorded at five different cooling rates $\left({ }^{\circ} \mathrm{C} \min ^{-1}\right)$ : (○) $2 ;(\bullet) 6 ;(\diamond) 10 ;(\diamond) 14 ;(\triangle) 18$.

athermal nucleation sites upon subsequent cooling. ${ }^{26}$

\section{DSC Measurements}

In the study of nonisothermal crystallization using DSC, the energy released during the crystallization process appears to be a function of temperature rather than of time as in the case of isothermal crystallization. Therefore, the relative crystallinity as a function of temperature $\theta(T)$ can be formulated as

$$
\theta(T)=\frac{\int_{T_{0}}^{T}\left(\frac{d H_{c}}{d T}\right) d T}{\Delta H_{c}}
$$

where $T_{0}$ and $T$ represent the crystallization onset and an arbitrary temperature, respectively; $d H_{c}$, the enthalpy of crystallization released during an infinitesimal temperature range $d T$; and $\Delta H_{c}$, the overall enthalpy of crystallization for a specific cooling condition.

\section{ANALYSIS, RESULTS, AND DISCUSSION}

Nonisothermal Crystallization and Melting Behavior

The crystallization exotherms of s-PP\#5 for nonisothermal crystallization from the melt at five different cooling rates ranging from 2 to $18^{\circ} \mathrm{C}$ $\min ^{-1}$ are presented in Figure 1. Clearly, the exothermic trace becomes wider and shifts to the lower-temperature region as the cooling rate increases, and this observation is apparently true for all of the s-PP samples studied in this article. Table II summarizes the characteristic data of 


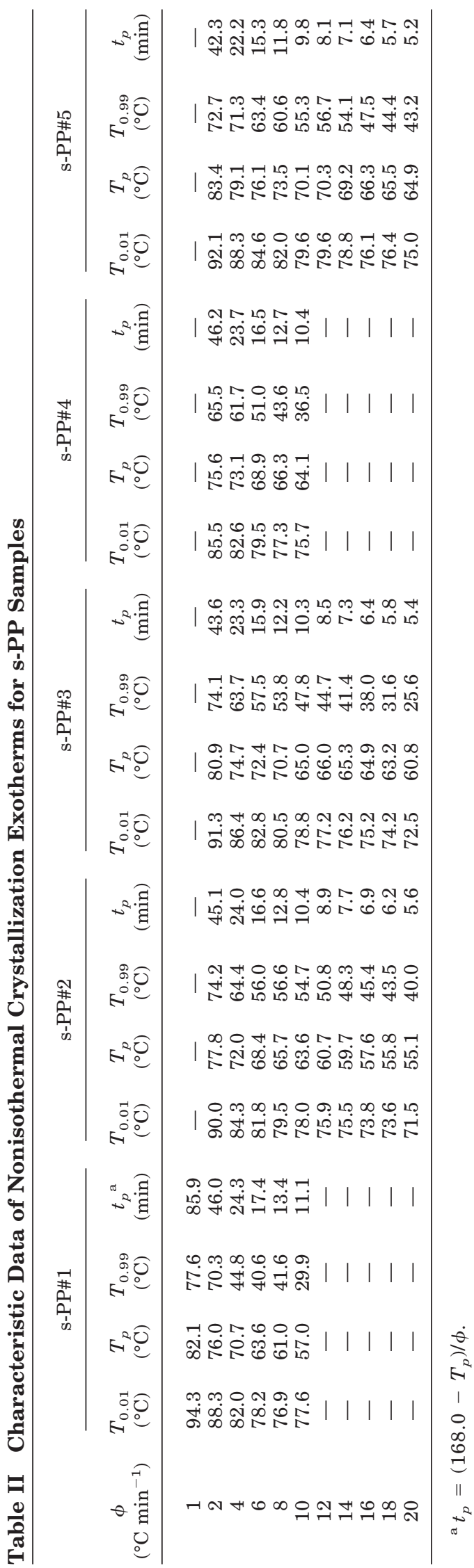

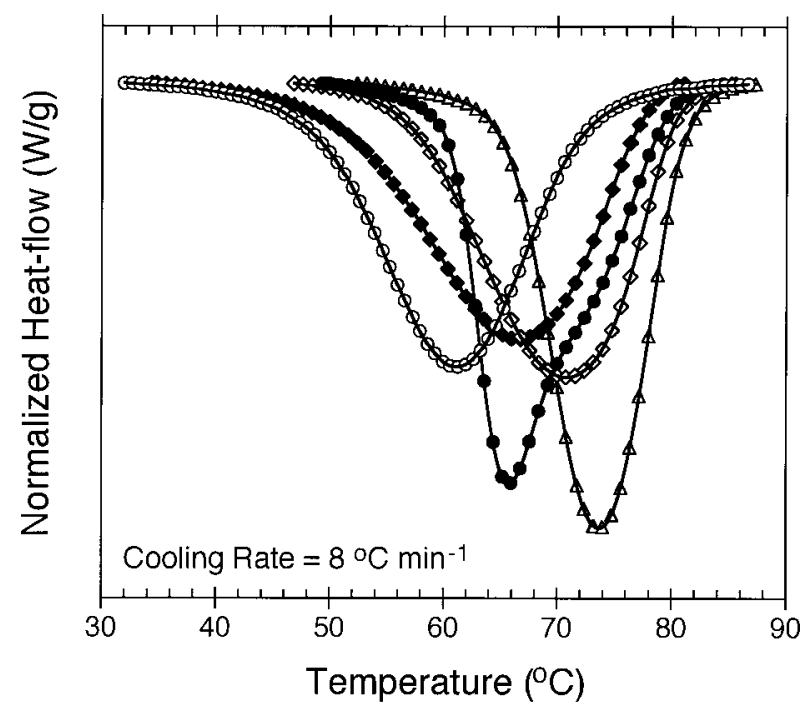

Figure 2 Nonisothermal melt crystallization exotherms of s-PP samples recorded at a cooling rate of $8^{\circ} \mathrm{C}$ $\min ^{-1}:(\bigcirc) \mathrm{s}-\mathrm{PP} \# 1 ;(\bullet) \mathrm{s}-\mathrm{PP} \# 2 ;(\diamond) \mathrm{s}-\mathrm{PP \#} 3 ;(\diamond) \mathrm{s}-\mathrm{PP} 4$; $(\triangle) \mathrm{s}-\mathrm{PP} \# 5$.

nonisothermal crystallization exotherms for all of the s-PP samples studied. For each s-PP sample, it is evident that, as the cooling rate increases, the temperature at $1 \%$ relative crystallinity $T_{0.01}$, the temperature at the maximum crystallization rate (i.e., peak temperature) $T_{p}$, and the temperature at $99 \%$ relative crystallinity $T_{0.99}$ are shifted to lower temperatures. The values of $T_{0.01}$ and $T_{0.99}$ will be used as a measure of the beginning and ending, respectively, of the crystallization process.

The nonisothermal crystallization exotherms for all of the s-PP samples, which were recorded at a cooling rate of $8^{\circ} \mathrm{C} \mathrm{min}^{-1}$, are plotted together in Figure 2. It is certain from Figure 2 that for a certain cooling rate s-PP\#5 crystallizes much faster than does s-PP\#1. An important parameter which is listed in Table II is the time $t_{p}$, which is denoted as the time the sample spends in order for its temperature to drop from a standard temperature in the melt $\left(\mathrm{ca} .168 .0^{\circ} \mathrm{C}\right.$ ) to a peak temperature (depending on the cooling rate studied). If the reciprocal value of the time $t_{p}$ (i.e., $t_{p}^{-1}$ ) is used to describe the rate of nonisothermal crystallization of s-PP, it is found that, for a certain $\mathrm{s}-\mathrm{PP}$ sample, as the cooling rate increases, the rate of nonisothermal crystallization also increases (cf. Fig. 3). It further suggests that for a certain cooling rate the rate of nonisothermal crystallization occurs in the following sequence: $\mathrm{s}-\mathrm{PP}$ 5 $>\mathrm{s}-\mathrm{PP \# 3}>\mathrm{s}-\mathrm{PP \# 2}>\mathrm{s}-\mathrm{PP \# 4}>\mathrm{s}-\mathrm{PP \# 1}$. 
Strikingly, the rate of isothermal crystallization among different samples, as suggested by plots of the reciprocal half-time $t_{0.5}^{-1}$ (or those of Avrami rate constant $k_{a}$ ) against the crystallization temperatures, also exhibits the same trend. ${ }^{11}$

Even though it is not entirely clear at this point why these S-PP samples crystallize in the aforementioned sequence, it is possible to establish a hypothesis to explain such a behavior based on the molecular information of these samples summarized in Table I. There are a number of factors affecting the rate of overall crystallization: They are, for example, the concentration of heterogeneous nuclei (including nucleation agents, if any), molecular weight and its distribution, the average amount of stereoirregular defects as well as that of regioirregular defects, and, finally, other types of intramolecular defects (e.g., comonomer defects). Information on the concentration of heterogeneous nuclei of all the samples needs to be further investigated; thus, it will not be included in our hypothesis.

According to Table I, it is apparent that the difference in the average amount of stereo-irregular defects is somewhat similar; thus, other factors such as the molecular weight and its distribution and the amount of ethylene defects may contribute to the crystallization behavior of these $\mathrm{s}-\mathrm{PP}$ samples observed. By disregarding other factors, comparison of the ethylene content (i.e., comonomer defect) among the different samples suggests that the rate of crystallization should occur in the following order: s-PP\#5 > s-PP\#4

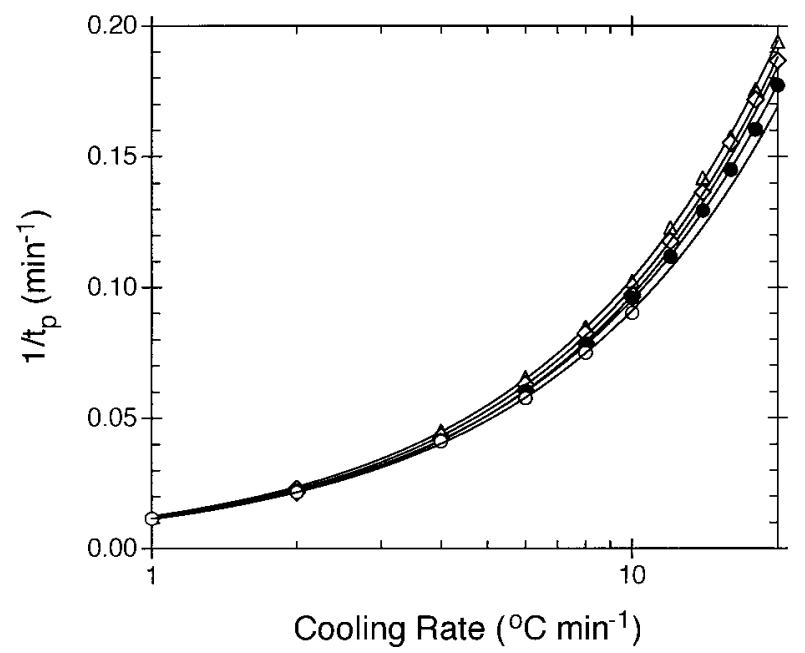

Figure 3 Rate of nonisothermal crystallization of sPP samples at different cooling rates: $(\bigcirc)$ s-PP\#1; s-PP\#2; $(\diamond)$ s-PP\#3; $(\diamond) \mathrm{s}-\mathrm{PP} 44 ;(\triangle) \mathrm{s}-\mathrm{PP}$ 5.

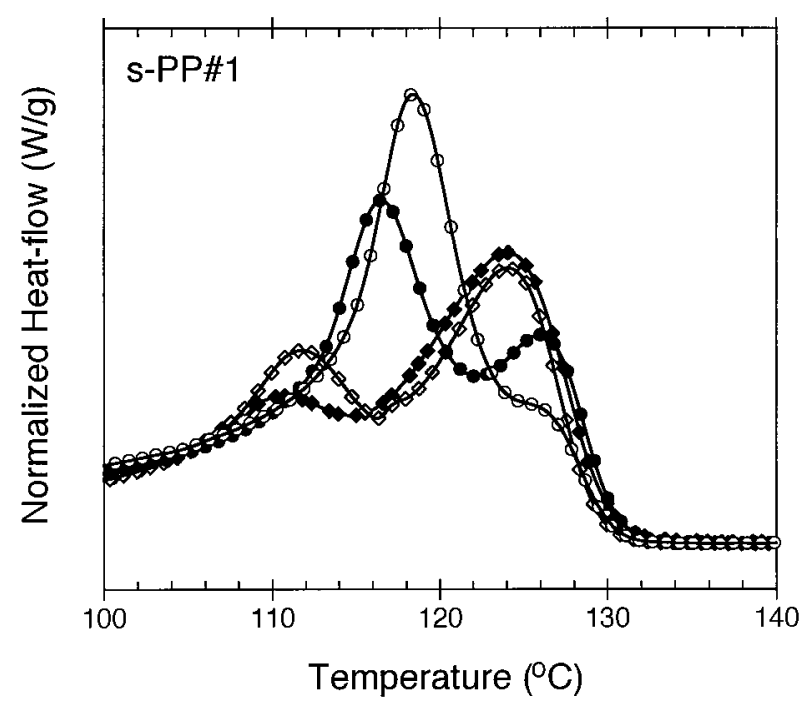

Figure 4 Subsequent melting endotherms of sample s-PP\#1 (recorded at a heating rate of $20^{\circ} \mathrm{C} \mathrm{min}{ }^{-1}$ ) after nonisothermal crystallization in DSC at four different cooling rates $\left({ }^{\circ} \mathrm{C} \min ^{-1}\right)$ : $(\bigcirc) 1 ;(\bullet) 2 ;(\diamond) 6 ;(\diamond) 10$.

$>$ s-PP\#3 > s-PP\#2 > s-PP\#1. On the contrary, it may be in the following sequence: $\mathrm{s}-\mathrm{PP} \# 5 \approx \mathrm{s}-$ $\mathrm{PP \# 3}>\mathrm{s}-\mathrm{PP} \# 2>\mathrm{s}-\mathrm{PP} \# 1>\mathrm{s}-\mathrm{PP} \# 4$, when judging from the molecular weight makeups. Postulating from this hypothesis, the experimental observation on the rate of crystallization following the order s-PP\#5 $>$ s-PP\#3 $>$ s-PP\#2 $>$ s-PP\#4 $>$ s$P P \# 1$ seems reasonable.

After crystallizing from the melt state at different cooling rates, each s-PP sample was subsequently heated at a rate of $20^{\circ} \mathrm{C} \mathrm{min}{ }^{-1}$ to the melt state, while its melting endotherm was recorded for further analysis. Some of the melting endotherms of s-PP\#1 after nonisothermal crystallization at four different cooling rates are shown, as examples, in Figure 4. It is apparent that the DSC endotherms exhibit double-melting peaks, with size and sharpness being dependent on the cooling rate studied. More specifically, with a decrease in cooling rate, the low-melting peak seems to increase in its size and sharpness and moves to higher temperature. On the contrary, the highmelting peak becomes smaller (and even disappears at $\phi=$ ca. $1^{\circ} \mathrm{C} \min ^{-1}$ ) as the cooling rate decreases. Figure 5 illustrates subsequent melting endotherms of all of the s-PP samples after nonisothermal crystallization at a cooling rate of $8^{\circ} \mathrm{C} \min ^{-1}$. Clearly, the two melting peaks are discernible on all of the endothermic traces. It should be noted that we also observed doublemelting phenomena in the study of isothermal crystallization of $\mathrm{s}-\mathrm{PP} .{ }^{10,11}$ 
Complete experimental data taken from the crystallization exotherms and the subsequent melting endotherms for all of the s-PP samples are summarized in Table III. It is apparent, according to Table III, that the peak temperature value of the low-melting endotherm $T_{\mathrm{ml}}$ and that of the high-melting one $T_{\mathrm{mh}}$ increase as the cooling rate decreases, with the $T_{\mathrm{mh}}$ values being less dependent on the cooling rate than those of $T_{\mathrm{ml}}$. Furthermore, it is evident that the values of both the enthalpy of crystallization $\Delta H_{c}$ and the enthalpy of fusion $\Delta H_{f}$ increase with a decreasing cooling rate. Since the weight percent absolute crystallinity $\chi_{c}$ can be calculated from the $\Delta H_{f}$ value through the following equation:

$$
\chi_{c}(\mathrm{wt} \%)=\frac{\Delta H_{f}}{\Delta H_{f}^{0}} \times 100,
$$

where $\Delta H_{f}^{0}$ is the enthalpy of fusion of an infinitely thick crystal [ca. $184.9 \mathrm{~J} \mathrm{~g}^{-1}$ (ref. 27)], it is apparent, based on the $\Delta H_{f}$ values summarized in Table III, that the absolute crystallinity $\chi_{c}$ is a decreasing function of the cooling rate. More specifically, $\chi_{c}$ ranges from 17.9 to $22.4 \%$ for s-PP\#1; from 19.1 to $21.8 \%$ for s-PP\#2; from 19.8 to $23.2 \%$ for s-PP\#3; from 17.6 to $20.8 \%$ for s-PP\#4; and, finally, from 20.4 to $23.9 \%$ for s-PP\#5.

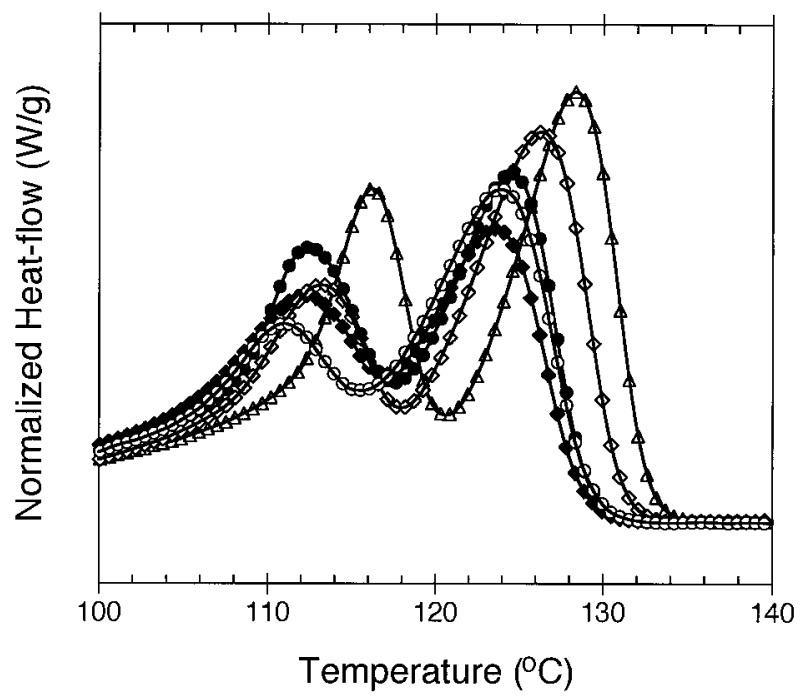

Figure 5 Subsequent melting endotherms of sPP samples (recorded at a heating rate of $20^{\circ} \mathrm{C} \mathrm{min}^{-1}$ ) after nonisothermal crystallization in DSC at a cooling rate of $8^{\circ} \mathrm{C}$ min $^{-1}:(\bigcirc) \mathrm{s}-\mathrm{PP} \# 1 ;(\bullet) \mathrm{s}-\mathrm{PP} \# 2 ;(\diamond) \mathrm{s}-\mathrm{PP} \#$; $(\diamond) \mathrm{s}-\mathrm{PP} 44 ;(\triangle) \mathrm{s}-\mathrm{PP}$ 5.

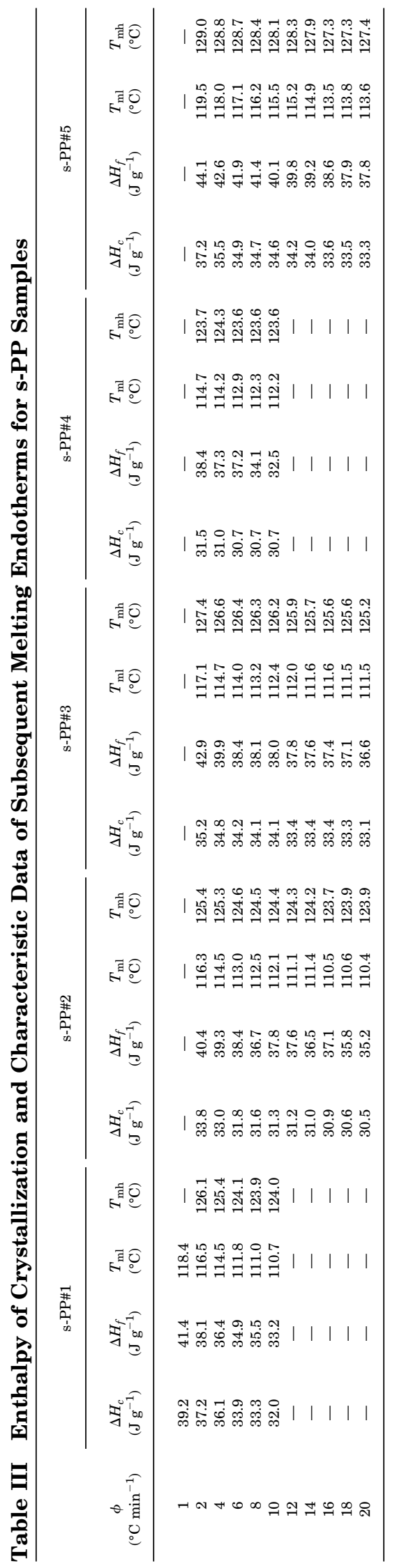




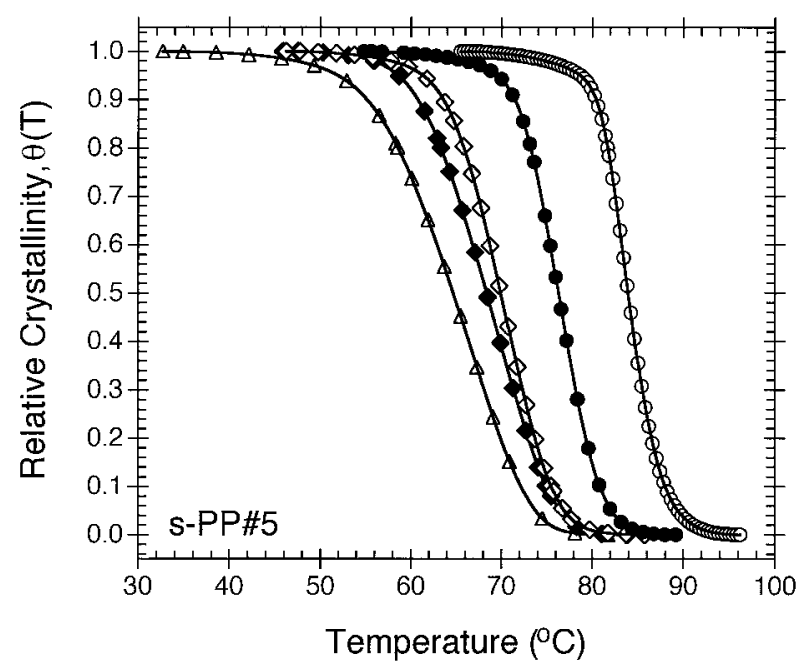

Figure 6 Relative crystallinity as a function of temperature of sample s-PP\#5 for five different cooling rates $\left({ }^{\circ} \mathrm{C} \min ^{-1}\right)$ : $(\bigcirc) 2 ;(\bullet) 6 ;(\diamond) 10 ;(\diamond) 14 ;(\triangle) 18$.

\section{Nonisothermal Crystallization Kinetics Based on Avrami Approach}

The most common approach used to describe the overall isothermal crystallization kinetics is the Avrami equation ${ }^{17}$ :

$$
\theta(t)=1-\exp \left(-k_{a} t^{n_{a}}\right),
$$

where $\theta(t)$ is the relative crystallinity as a function of time; $k_{a}$, the Avrami crystallization rate constant; $n_{a}$, the Avrami exponent (which constitutes the growth and nucleation behavior); and $t$, the time taken during the crystallization process (the incubation time $t_{0}$ is excluded). Both $k_{a}$ and $n_{a}$ are constants typical of a given crystalline morphology and type of nucleation at a particular crystallization condition. ${ }^{28}$ Practically, parameters $k_{a}$ and $n_{a}$ can readily be calculated from the least-square line fit to the double logarithmic plot of $\ln [-\ln (1-\theta(t))]$ versus $\ln (t)$, where $k_{a}$ is taken as the antilogarithmic value of the $y$-intercept and $n_{a}$ is simply the slope (calculated for 10 to $80 \%$ relative crystallinity only).

For the experimental data to be analyzed using eq. (3), it is mandatory that the relative crystallinity be a function of time. Since we know that from the study of nonisothermal crystallization using DSC, the energy released during the crystallization process naturally relates to the relative crystallinity as a function of temperature through eq. (1). Figure 6 illustrates examples of the relative crystallinity as a function of temper- ature of s-PP\#5 for five different cooling rates: each curve was calculated using eq. (1) from the corresponding exotherm shown in Figure 1. In DSC, the relative crystallinity as a function of time can be obtained from the similar plots shown in Figure 6 based on the assumption that the sample experiences the same thermal history as determined by the DSC furnace. This may be realized only when the thermal lag between the sample and the furnace is kept minimal. If this assumption is valid, the horizontal temperature scale, such as shown in Figure 5, can be transformed into the time domain using the following relationship:

$$
t=\frac{T_{0}-T}{\phi} .
$$

The plots of relative crystallinity as a function of time $\theta(t)$ of all of the s-PP samples for various cooling rates are illustrated in Figure 7 (raw data are shown in the figure as points). It is clear from the plots that the faster the cooling rate, the shorter the time needed for the completion of the crystallization process.

An important parameter which can be taken directly from a plot of relative crystallinity as a function of time is the half-time of crystallization $t_{0.5}$, which is the change in time from the onset of crystallization to the time at 50\% completion. Based on eq. (3), the Avrami crystallization kinetics parameters $\left(n_{a}\right.$ and $\left.k_{a}\right)$ can be extracted though the double logarithmic plot of $\ln [-\ln (1$ $-\theta(t))$ ] versus $\ln (t)$, as mentioned previously. Values of $n_{a}$ and $k_{a}$ as well as the crystallization half-time $t_{0.5}$ for all of the s-PP samples are summarized in Table IV. For all the s-PP samples, the Avrami exponent $n_{a}$ ranges from 2.37 to 5.27 and is found to decrease in value as the cooling rate increases. More specifically, $n_{a}$ ranges from 4.32 to 5.27 for s-PP\#1; from 2.96 to 3.70 for s-PP\#2; from 2.37 to 4.60 for s-PP\#3; from 2.48 to 3.86 for s-PP\#4; and, lastly, from 3.00 to 4.83 for s-PP\#5.

The rate of nonisothermal crystallization can readily be described by the values of the Avrami crystallization rate constant $k_{a}$ and the crystallization half-time $t_{0.5}$ (or, more specifically, the reciprocal value of the crystallization half-time $t_{0.5}^{-1}$. The result shows that, for each s-PP sample, the rate of nonisothermal crystallization varies proportionally with the cooling rate. In other words, the rate of crystallization increases as the cooling rate increases. It is worth noting that, for 

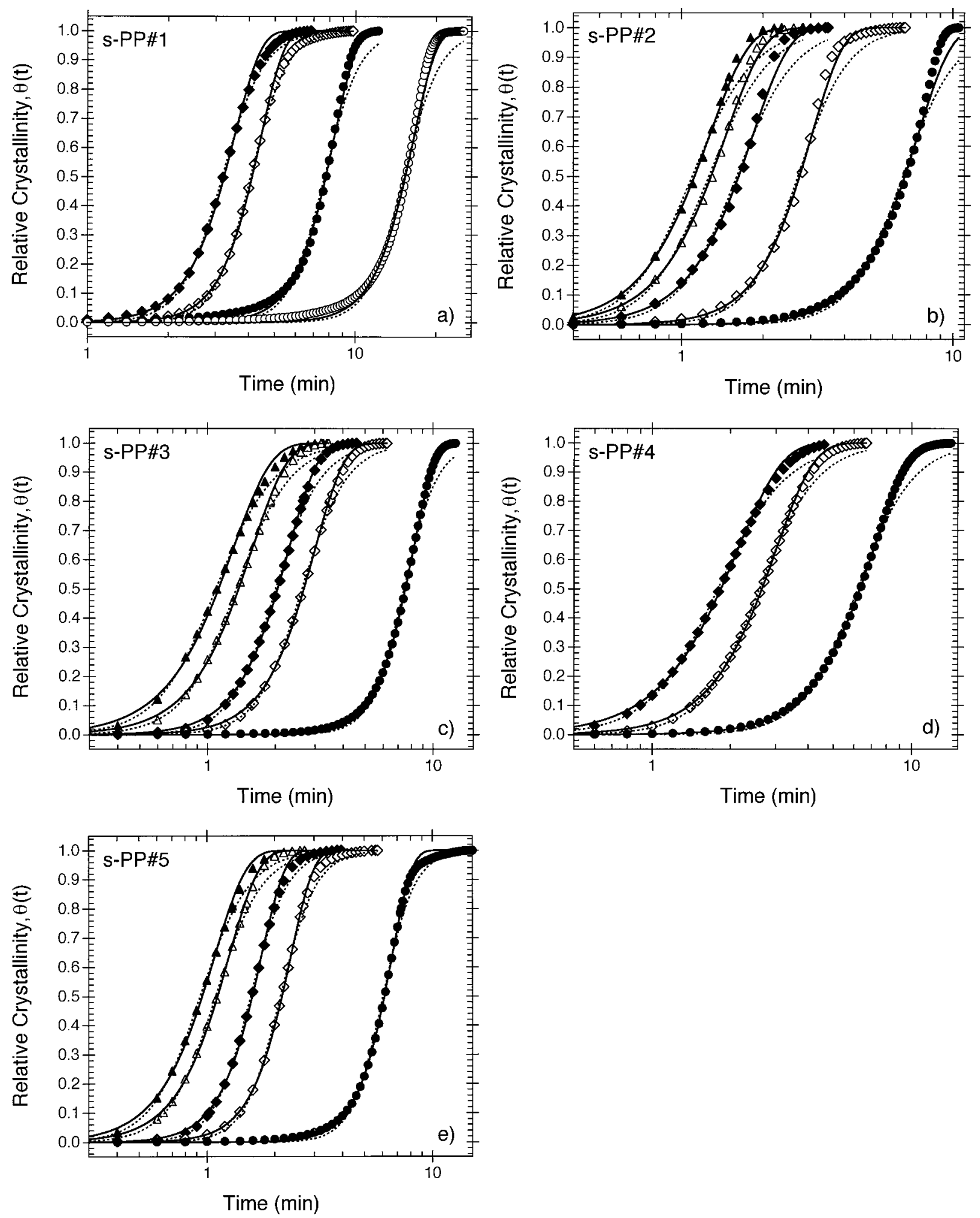

Figure 7 Relative crystallinity as a function of time of (a) s-PP\#1, (b) s-PP\#2, (c) $\mathrm{s}-\mathrm{PP \# 3}$, (d) s-PP\#4, and (e) s-PP\#5 for various cooling rates $\left({ }^{\circ} \mathrm{C} \mathrm{min}^{-1}\right)$ : (○) $1 ;(\bullet) 2 ;(\diamond)$ $6 ;(\diamond) 10 ;(\triangle) 14 ;(\Delta) 18$. Model prediction based on Avrami and Tobin equations are also shown as solid and dashed lines, respectively. 


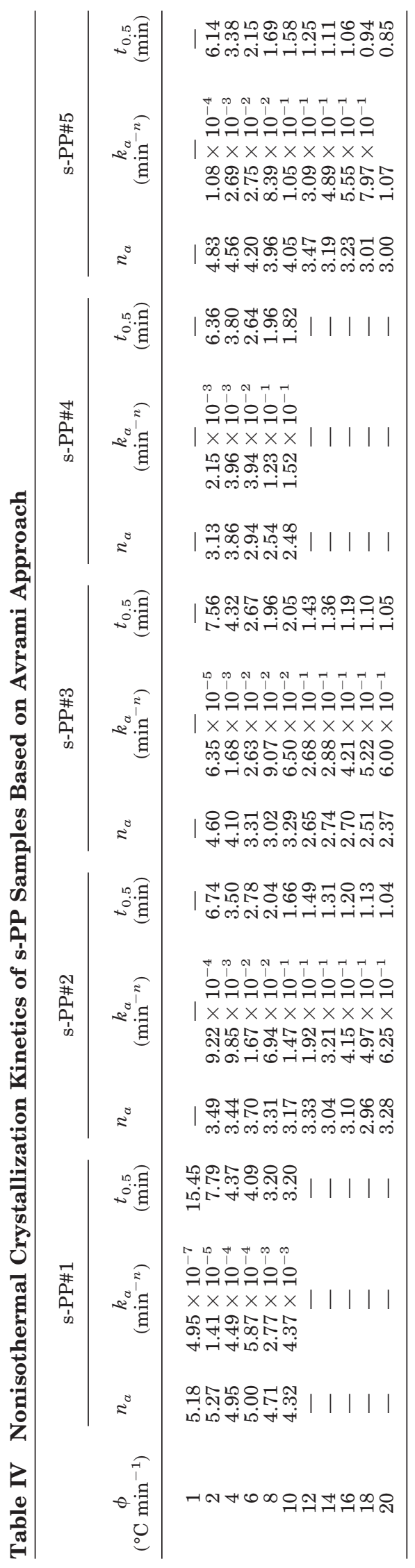

$\mathrm{s}-\mathrm{PP} \# 1$ and $\mathrm{s}-\mathrm{PP} \# 4$, the cooling rate may not be higher than $10^{\circ} \mathrm{C} \mathrm{min}{ }^{-1}$ for the completion of the crystallization process to occur during cooling from the melt. At cooling rates greater than $10^{\circ} \mathrm{C}$ $\min ^{-1}$, some crystallizable material will still be uncrystallized as the temperature drops into the subglass region [the glass transition $T_{g}$ of all of the s-PP samples studied in this article was determined to be around $-6.1^{\circ} \mathrm{C}$ (ref. 11)], and it will crystallize upon subsequent heating (this process is known as cold crystallization).

\section{Nonisothermal Crystallization Kinetics Based on Tobin Approach}

An important consideration for the Avrami approach is that the model is only appropriate for the early stages of crystallization. The complications arise due to the effects of growth site impingement and secondary crystallization process, which were disregarded for the sake of simplicity in the original derivation of the model. A theory of phase transformation kinetics with growth site impingement was proposed by Tobin. ${ }^{18}$ According to this approach, the equation of phase transition reads

$$
\theta(t)=\frac{k_{t} t^{n_{t}}}{1+k_{t} t^{n_{t}}}
$$

where $\theta(t)$ is the relative crystallinity as a function of time; $k_{t}$ the Tobin crystallization rate constant; and $n_{t}$, the Tobin exponent. Based on this proposition, the exponent of time $n_{t}$ needs not be integral as it is governed directly by different types of nucleation and growth mechanisms.

Based on the raw data of the relative crystallinity as a function of time $\theta(t)$ such as those shown as points in Figure 7 for all of the s-PP samples, Tobin crystallization kinetics parameters $\left(k_{t}\right.$ and $\left.n_{t}\right)$ can be extracted by drawing a least-square line fit to the double logarithmic plot of $\ln [\theta(t) /(1-\theta(t))]$ versus $\ln (t)$, where $k_{t}$ is taken as the antilogarithmic value of the $y$-intercept and $n_{t}$ is simply the slope (calculated for $10-80 \%$ relative crystallinity only). Values of $n_{t}$ and $k_{t}$ for all of the s-PP samples are summarized in Table V. For all the s-PP samples, the Tobin exponent $n_{t}$ ranges from 3.14 to 6.70 and is found to decrease in value as the cooling rate increases. More specifically, $n_{t}$ ranges from 5.63 to 6.70 for $\mathrm{s}-\mathrm{PP} \# 1$; from 3.84 to 4.72 for $\mathrm{s}-\mathrm{PP} \# 2$; from 3.14 to 5.92 for s-PP\#3; from 3.27 to 5.03 for s-PP\#4; and, 


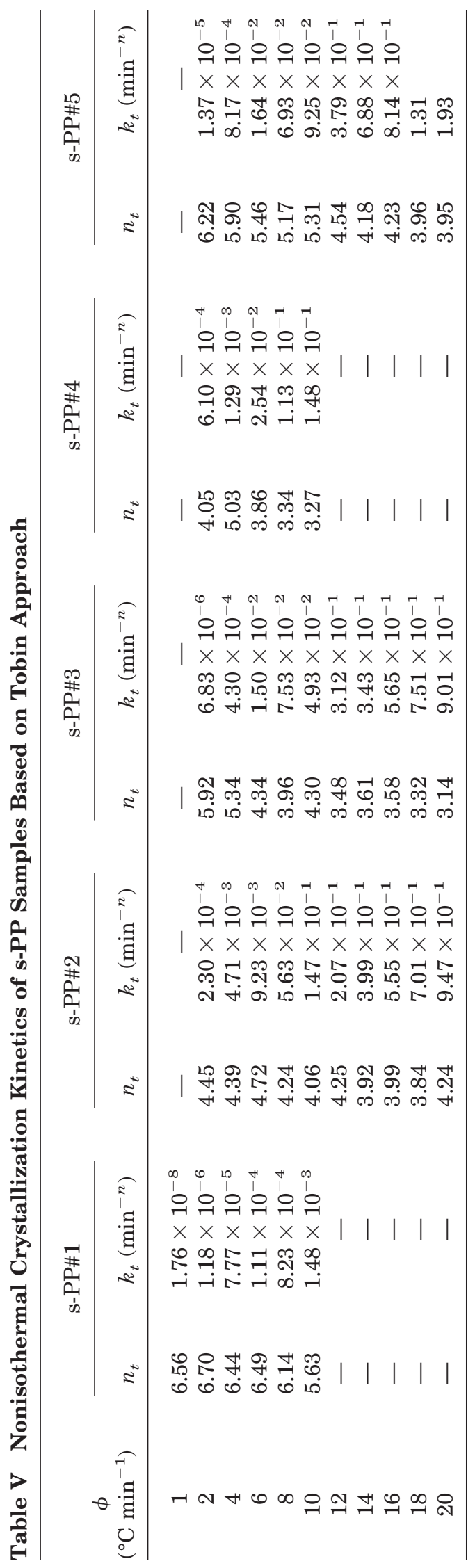

lastly, from 3.95 to 6.22 for s-PP\#5. Similar to what the Avrami crystallization rate constant $k_{a}$ and the reciprocal value of the half-time $t_{0.5}^{-1}$ suggested, the Tobin crystallization rate constant $k_{t}$ suggests that, for each s-PP sample, the rate of nonisothermal crystallization increases as the cooling rate increases.

\section{Comparison of the Results Obtained from Avrami and Tobin Approaches}

A direct comparison between the results obtained from the Avrami approach (cf. Table IV) and from the Tobin approach (cf. Table V) shows that the Avrami crystallization rate constant $k_{a}$ is approximately 10 -fold greater than is the Tobin crystallization rate constant $k_{t}$, especially at a low cooling rate (i.e., $2^{\circ} \mathrm{C} \min ^{-1}$ ), but they become more comparable as the cooling rate increases. In addition, it is apparent that at the same cooling rate the Avrami exponent $n_{a}$ is always smaller in value than is the Tobin exponent $n_{t}$. By taking the average of the difference between the two values, we are able to conclude based on our experimental observation that $n_{t} \approx n_{a}+1$.

The best way of testing the efficiency of both approaches in describing the nonisothermal crystallization kinetics is to reconstruct the relative crystallization as a function of time $\theta(t)$ for each cooling condition using the mathematical eqs. (4) and (5). Based on the kinetic results summarized in Tables IV and V, the reconstructed $\theta(t)$ curves for all of the s-PP samples are shown in Figure 7(a-e). It should be noted, according to Figure 7, that the Avrami prediction is shown as solid lines, whereas the Tobin prediction, as dashed lines.

According to Figure 7, it is apparent that both models provide a reasonably good fit to the experimental data for the relative crystallinity $\theta(t)$ in the range of $0.15-0.75$. In the lower relative crystallinity range [ca. $\theta(t) \leq 0.15$ ], both models seem to provide a fair fit to the experimental data. For the majority of the plots, both models seem to underpredict the evolution of the relative crystallinity with time, with the Tobin prediction being the worst of the two. In the higher relative crystallinity range [ca. $\theta(t) \geq 0.75$ ], the Tobin model always underpredicts the evolution of the relative crystallinity with time. This may be because the model as shown in eq. (5) was the simplified form of a rather more complicated mathematical model described in the original publications ${ }^{18}$ or perhaps due to the overprediction of the impingement effect. However, the Tobin model seems to 


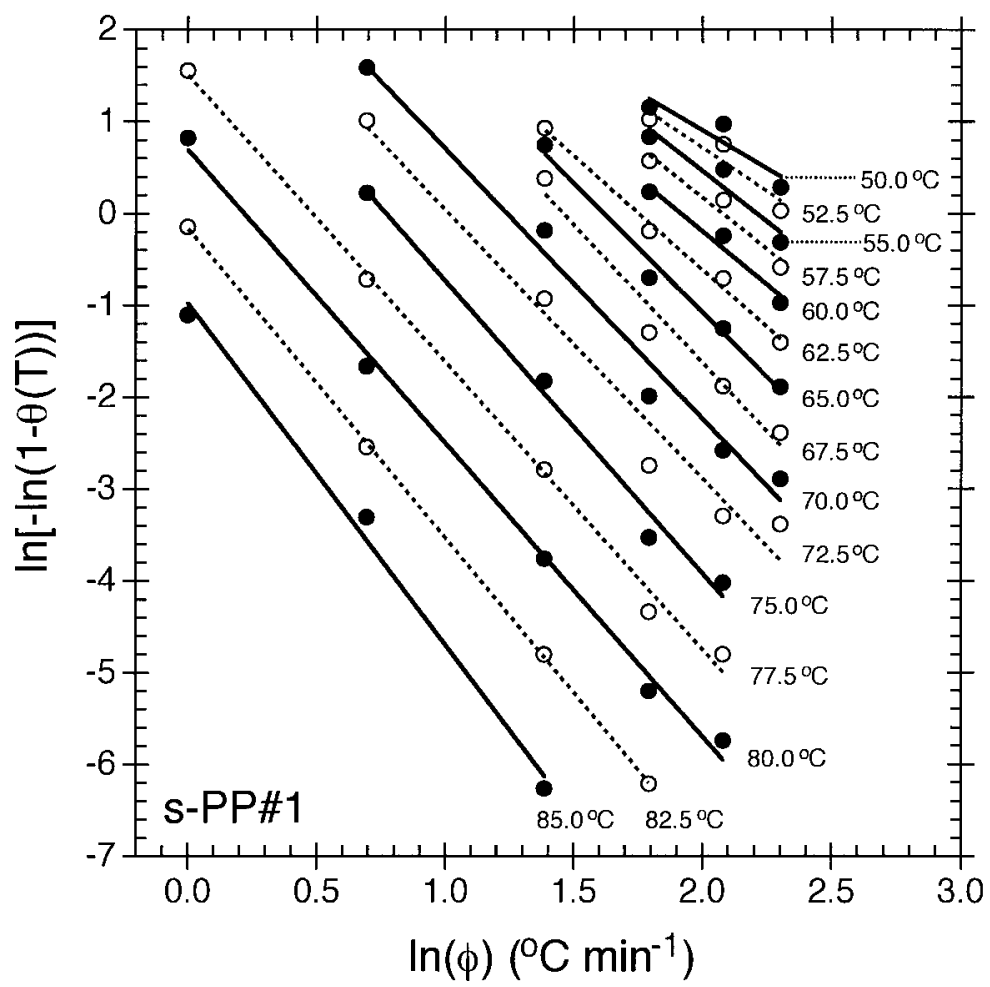

Figure 8 Typical Ozawa analysis based on the nonisothermal crystallization data of s-PP\#1 (see ref. 16 for more details).

give a fair fit to the experimental data at higher cooling rates. On the contrary to the Tobin prediction, the Avrami model seems to give a fair fit to the experimental data at low cooling rates and tends to overpredict the evolution of the relative crystallinity with time as the cooling rate increases.

\section{Nonisothermal Crystallization Kinetics Based on Ozawa Approach}

Based on the mathematical derivation of Evans, ${ }^{29}$ Ozawa $^{19}$ extended the Avrami theory ${ }^{17}$ to be able to describe the nonisothermal case. Mathematically, the relative crystallinity can be written as a function of cooling rate according to the following equation:

$$
\theta(T)=1-\exp \left(-\frac{k_{o}}{\phi^{n_{o}}}\right)
$$

where $\theta(T)$ is the relative crystallinity as a function of temperature for a fixed temperature; $k_{o}$, the Ozawa crystallization rate constant; and $n_{o}$, the Ozawa exponent (which is similar to the Avrami exponent).

The data can be taken directly from the raw $\theta(T)$ data similar to those shown as examples for s-PP\#5 in Figure 6, and the analysis can be performed through a double logarithmic plot of $\ln [-\ln (1$ $-\theta(T))]$ versus $\ln (\phi)$ for a fixed temperature. Figure 8 illustrates such plots based on the nonisothermal crystallization data of s-PP\#1 (cf. ref. 16 for more detail) for a series of temperatures ranging from 50 to $85^{\circ} \mathrm{C}$. A least-square line is drawn to data points taken for each temperature. The Ozawa crystallization rate constant $k_{o}$ is taken as the antilogarithmic value of the $y$-intercept (i.e., $k_{o}=e^{y \text {-intercept }}$ ), and the Ozawa exponent $n_{o}$ is taken as the negative value of the slope (i.e., $n_{o}=$-slope). It is important to note that results will only be taken from least-square lines drawn through plots of at least three points, and this is the reason why the temperature range varies from sample to sample (they all lie, however, in the range of 50 to $85^{\circ} \mathrm{C}$ ). Values of $n_{o}$ and $k_{o}$ as well as the corresponding correlation coefficient $r^{2}$ of the fit for all of the $\mathrm{s}-\mathrm{PP}$ samples studied in this article are summarized in Table VI. 


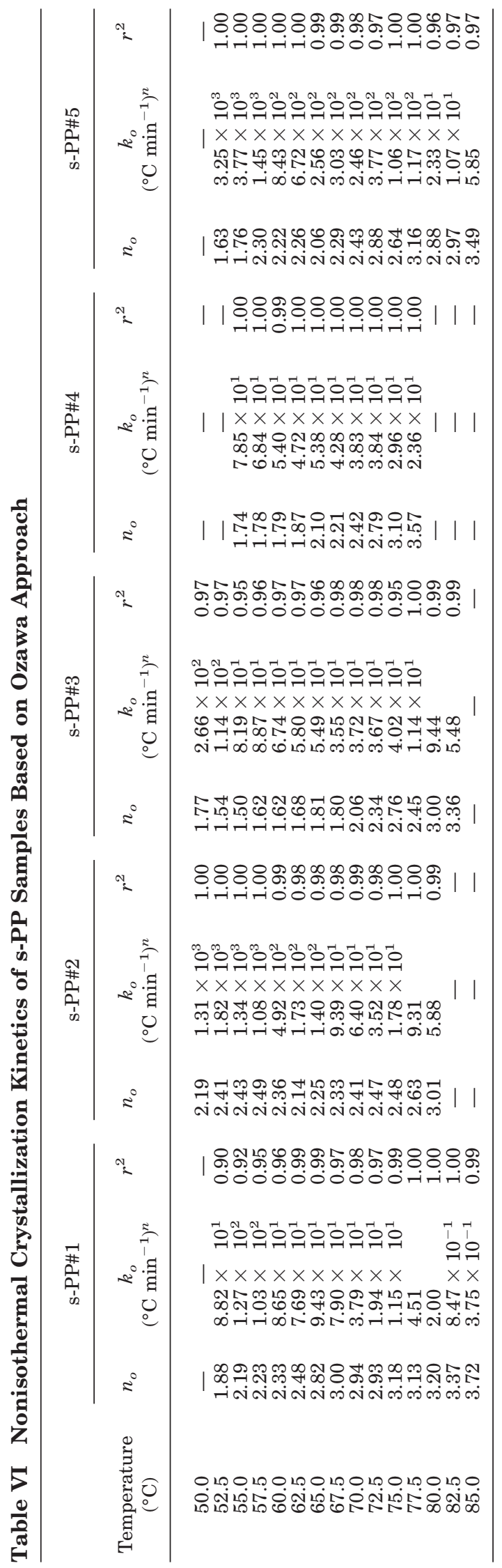

Based on the correlation coefficient $r^{2}$ summarized in Table VI, it is fair to conclude that the Ozawa approach is found to be a satisfactory description of the nonisothermal crystallization kinetics of s-PP. For all the s-PP samples, the Ozawa exponent $n_{o}$ is found to roughly increase with an increase in temperature and lies within the range of 1.63-3.72. More specifically, $n_{o}$ ranges from 1.88 to 3.72 for $\mathrm{s}-\mathrm{PP} \# 1$; from 2.14 to 3.01 for s-PP\#2; from 1.50 to 3.36 for s-PP\#3; from 1.74 to 3.57 for s-PP\#4; and, lastly, from 1.63 to 3.49 for s-PP\#5. For each s-PP sample, the resulting Ozawa exponents $n_{o}$ are, amazingly, very comparable to the Avrami exponents $n_{a}$ that we found in our earlier results ${ }^{10,11}$ on isothermal bulk crystallization kinetics of s-PP within the similar temperature range. For each s-PP sample, the Ozawa rate constant $k_{o}$ is found to decrease with increasing temperature (with the temperature range of interest), suggesting that s-PP crystallizes slower with an increase in temperature.

\section{Nonisothermal Crystallization Kinetics Based on Ziabicki's Kinetic Crystallizability Approach}

Instead of describing the crystallization process with complicated mathematical models, Ziabicki $^{20-22}$ proposed that phase transformation kinetics can also be described by a first-order kinetic equation:

$$
\frac{d \theta(t)}{d t}=K(T)[1-\theta(t)]
$$

where $\theta(t)$ is the relative crystallization as a function of time and $K(T)$ is a crystallization rate function which is only dependent on temperature. In the case of nonisothermal crystallization, functions $K(T)$ and $\theta(t)$ vary and are dependent on the cooling rates studied.

For a given cooling condition, Ziabicki ${ }^{20-22}$ showed that the crystallization rate function $K(T)$ can be described by a Gaussian function of the form

$$
K(T)=K_{\max } \exp \left[-4 \ln 2 \frac{\left(T_{c}-T_{\max }\right)^{2}}{D^{2}}\right],
$$

where $T_{\max }$ is the temperature where the crystallization rate is the maximum; $K_{\max }$, the crystallization rate at $T_{\text {max }}$; and $D$, the half-width of the crystallization rate-temperature function. With 
use of the isokinetic approximation, integration of eq. (8) over the whole range of temperatures, for a given cooling condition, in which crystallization may occur $\left(T_{g}<T<T_{m}^{0}\right)$ leads to an important characteristic value describing the crystallization ability of the polymer, namely, the kinetic crystallizability $G$ :

$$
\int_{T_{g}}^{T_{m}^{0}} K(T) d T \approx 1.064 K_{\max } D=G .
$$

According to the approximate theory, ${ }^{20}$ the kinetic crystallizability $G$ characterizes the degree of crystallinity obtained when the polymer is cooled at unit cooling rate from the melting temperature to the glass transition temperature. ${ }^{22}$

In the case of nonisothermal crystallization studies in DSC where cooling rate is a variable, eq. (9) can be applied by replacing the crystallization rate function $K(T)$ with a derivative function of the relative crystallinity $\dot{\theta}_{\phi}(T)$ specific for each cooling rate studied (i.e., crystallization rate function at different cooling rate). Therefore, eq. (9) is rewritten to be

$$
\int_{T_{g}}^{T_{m}^{0}} \dot{\theta}_{\phi}(T) d T \approx 1.064 \times \dot{\theta}_{\max , \phi} D_{\phi}=G_{\phi}
$$

where $\dot{\theta}_{\max , \phi}$ and $D_{\phi}$ are the maximum crystallization rate and the half-width observed on corresponding derivative function $\dot{\theta}_{\phi}(T)$. According to eq. (10), $G_{\phi}$ is the kinetic crystallizability at an arbitrary cooling rate $\phi$; the kinetic crystallizability at unit cooling rate $G$ can therefore be obtained by normalizing $G_{\phi}$ with $\phi$ (i.e., $G=G_{\phi} / \phi$ ). It should be noted that this procedure was first realized by Jeziorny. ${ }^{30}$

Complete experimental results of the determination of parameters characterizing the nonisothermal crystallization of s-PP based on Ziabicki's kinetic crystallizability approach are summarized in Table VII. For each s-PP sample, the temperature at the maximum crystallization rate $T_{\max }$ is found to decrease with an increasing cooling rate, whereas both the maximum crystallization rate, $\dot{\theta}_{\text {max }, \phi}$, and $D_{\phi}$, the half-width of the crystallization rate function $\dot{\theta}_{\phi}(T)$, are found to increase with an increasing cooling rate. Based on these values, the resulting $G_{\phi}$ value (not listed in Table VII) is therefore an increasing function of the cooling rate. After normalizing the effect of the

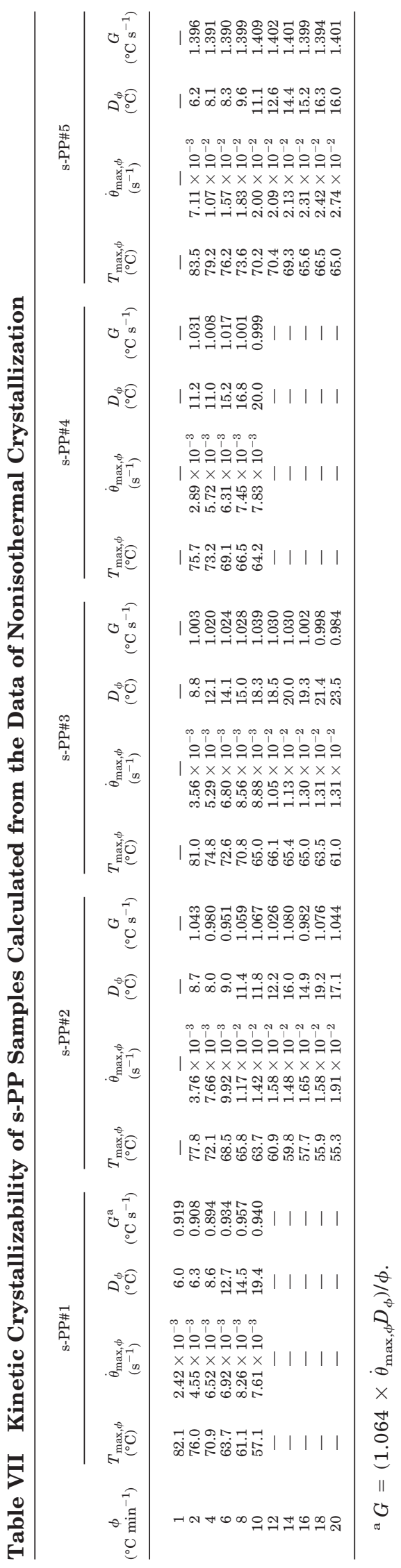


Table VIII Kinetic Crystallizability of s-PP and Some Other Polymers

\begin{tabular}{lcl}
\hline & Kinetic \\
Polymer & $\begin{array}{c}\text { Crystallizability } \\
G\left({ }^{\circ} \mathrm{C} \mathrm{s}^{-1}\right)\end{array}$ & \multicolumn{1}{c}{ References } \\
\hline s-PP\#1 & $0.925(0.412)$ & This work and ref. 11 \\
s-PP\#2 & $1.031(1.559)$ & This work and ref. 11 \\
s-PP\#3 & $1.016(1.338)$ & This work and ref. 11 \\
s-PP\#4 & $1.011(0.839)$ & This work and ref. 11 \\
s-PP\#5 & $1.398(2.141)$ & This work and ref. 11 \\
i-PS & 0.16 & Ref. 22 \\
i-PP & 35 & Ref. 22 \\
Nylon 6 & 6.8 & Ref. 22 \\
Nylon 66 & 139 & Ref. 22 \\
PET & 1.1 & Ref. 22
\end{tabular}

cooling rate from the resulting $G_{\phi}$ values, the values of the kinetic crystallizability at the unit cooling rate $G$ are comparable (cf. Table VII).

Table VIII summarizes the average $G$ value for each s-PP sample studied in this article, along with the $G$ values calculated earlier ${ }^{11}$ from the isothermal half-time of the crystallization data in parentheses. The characteristic $G$ values of some other polymers ${ }^{22}$ are also listed for comparison. Since, as mentioned previously, the practical meaning of the kinetic crystallizability $G$ is to characterize the ability of polymers in crystallizing when it is cooled from the melting temperature to the glass transition temperature at a unit cooling rate, the higher the $G$ values, the more readily the polymer crystallizes. Based on the $G$ values summarized in Table VIII, the crystallization ability of the s-PP samples studied falls in the following sequence: s-PP\#5 $>$ s-PP\#2 $>$ s$\mathrm{PP \# 3}>\mathrm{s}-\mathrm{PP} \# 4>\mathrm{s}-\mathrm{PP} \# 1$. When comparing with some other polymers also listed in Table VIII, the crystallization ability of these polymers falls in the following order: nylon $66>$ i-PP $>$ nylon 6 $>\mathrm{s}-\mathrm{PP} \approx \mathrm{PET}>\mathrm{i}-\mathrm{PS}$.

\section{Effective Activation Energy Describing the Overall Crystallization Process}

A number of mathematical methods ${ }^{23-25}$ were proposed for the analysis of data obtained from nonisothermal thermoanalytical investigations of crystallization of glass-forming liquids (more references can be found in a very good critical review publication by Yinnon and Uhlmann ${ }^{31}$ ). The theoretical basis for the interpretation of the nonisothermal crystallization data taken from thermo- analytical device (e.g., DTA or DSC) proposed by most of these researchers is provided by the theory of solid-state phase transformation developed by Avrami ${ }^{17}$ and others. ${ }^{29,32,33}$ Based on eq. (3) (Avrami equation), the crystallization rate constant $k_{a}$ is usually described by an Arrheniustype dependence of temperature:

$$
k_{a}^{1 / n_{a}}=k_{a 0} \exp \left(-\frac{\Delta E}{R T}\right)
$$

where $k_{a 0}$ is a temperature-independent preexponential factor; $\Delta E$, the effective activation energy describing the overall crystallization process; and $R$, the universal gas constant.

In the case of the isothermal crystallization experiment using DSC, the effective activation energy $\Delta E$ can be calculated directly based on the relationship of the isothermal Avrami kinetics parameters $\left(k_{\alpha}\right.$ and $\left.n_{\alpha}\right)$ on the crystallization temperature $T_{c}$ set forth in eq. (11). Specifically, the effective activation energy $\Delta E$ can be determined from the slope of the plot of $\left(1 / n_{a}\right) \ln \left(k_{a}\right)$ versus $1 / T_{c}$ (i.e., $\Delta E=-R \times$ slope). In the case of a nonisothermal crystallization experiment using DSC, the effective activation energy $\Delta E$ can be evaluated from methods such as those proposed by Augis and Bennett, ${ }^{23}$ Kissinger, ${ }^{24}$ or Takhor. ${ }^{25}$ The main objective of these methods is to find a finite relationship between the peak temperatures $T_{p}$ obtained from the nonisothermal crystallization exotherms and the cooling rates $\phi$ (or heating rate) used.

Considering the variation of the peak temperature $T_{p}$ with the cooling rate $\phi$ (cf. Table II), the effective activation energy $\Delta E$ can be evaluated based on plots of the following forms: (1) AugisBennett method,

$$
\frac{d\left[\ln \left(\phi /\left(T_{0}-T_{p}\right)\right)\right]}{d\left(1 / T_{p}\right)}=-\frac{\Delta E}{R}
$$

where $T_{0}$ is an initial temperature (ca. $168^{\circ} \mathrm{C}$ for s-PP); (2) Kissinger method,

$$
\frac{d\left[\ln \left(\phi / T_{p}^{2}\right)\right]}{d\left(1 / T_{p}\right)}=-\frac{\Delta E}{R}
$$

and (3) Takhor method,

$$
\frac{d[\ln (\phi)]}{d\left(1 / T_{p}\right)}=-\frac{\Delta E}{R}
$$



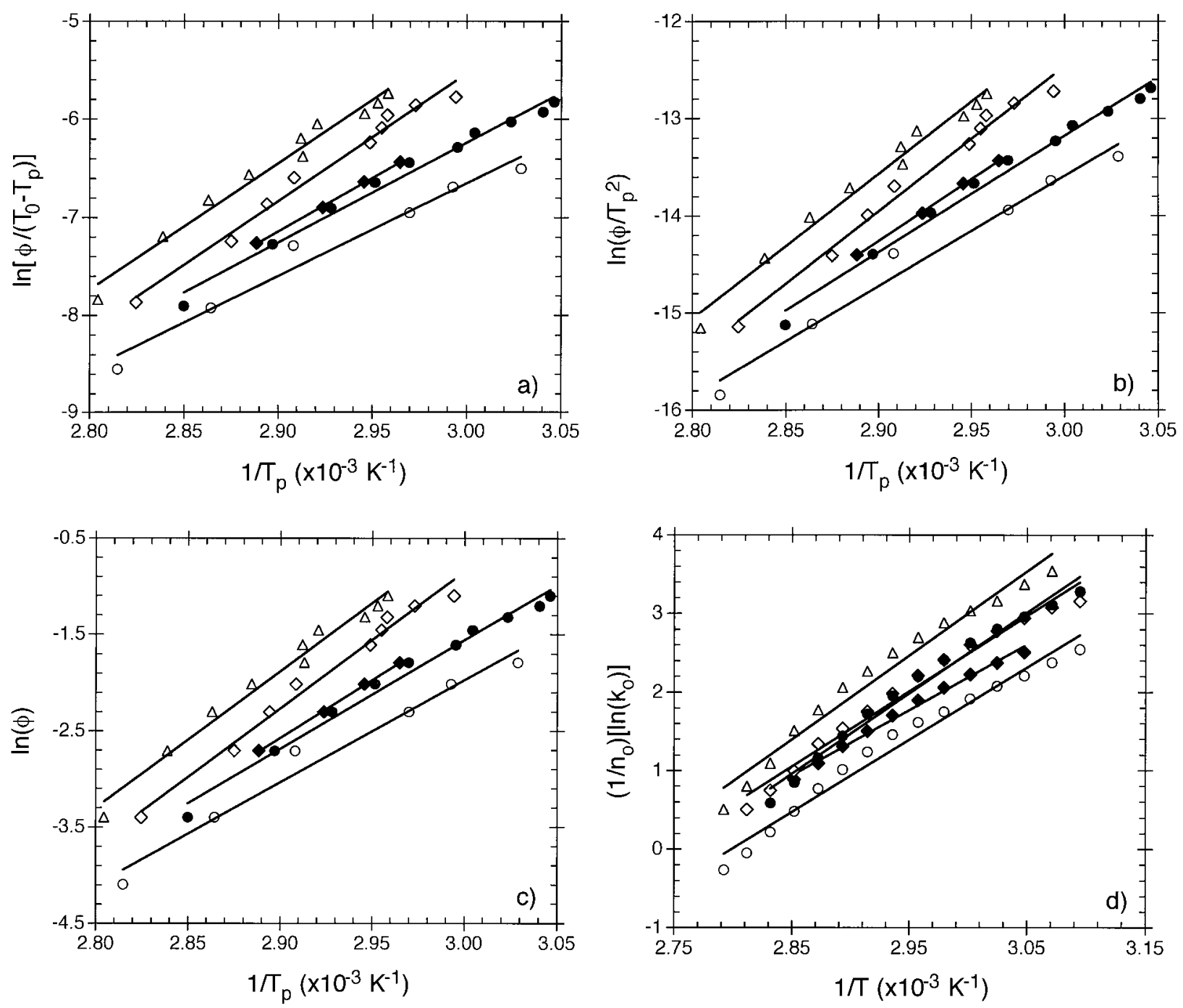

Figure 9 Determination of the effective activation energy $\Delta E$ describing the overall crystallization process for all of the s-PP samples based on (a) the Augis-Bennett method, (b) the Kissinger method, (c) the Takhor method, and (d) the Arrhenius-type temperature dependence of the Ozawa kinetics results shown in Table VI: $(\bigcirc)$ s-PP\#1;

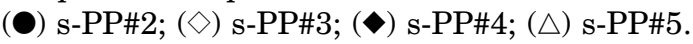

It is important to note that different assumptions utilized by these authors during mathematical derivations for the sake of simplicity resulted in different relationships between $T_{p}$ and $\phi$, as evidenced in eqs. (12)-(14). According to the critical review publication by Yinnon and Uhlmann, ${ }^{31}$ the Augis-Bennett method was found to be the most theoretically correct.

Figure $9(\mathrm{a}-\mathrm{c})$ illustrate plots based on the $\mathrm{Au}-$ gis-Bennett method, the Kissinger method, and the Takhor method, respectively. The slopes of the least-square lines drawn through these plots equal $-\Delta E / R$; thus, the effective activation energy $\Delta E$ can be calculated accordingly. We also calculated the effective activation energy $\Delta E$ from the nonisothermal crystallization data carried out by Rodriguez-Arnold* and $\mathrm{Xu}$ et al. ${ }^{\dagger}$ With the correlation coefficient $r^{2}$ ranging from 0.95 to 1.00 , the bulk of the data complies well with all of the methods tested. It is worth noting that even though the Augis-Bennett method is the most accurate we feel that calculation of the $\Delta E$ values using the Kissinger and Takhor methods was

\footnotetext{
* Evaluated from the nonisothermal crystallization data summarized in Table 5.2 of ref. 8 .

$\dagger$ Evaluated from the nonisothermal crystallization data summarized in Table II of ref. 15.
} 
Table IX Effective Activation Energy $\Delta E$ Describing the Overall Crystallization Process of Various s-PP Samples

\begin{tabular}{|c|c|c|c|c|c|c|c|c|c|}
\hline \multirow[b]{2}{*}{ Sample } & \multirow[b]{2}{*}{$M_{\eta}$} & \multirow[b]{2}{*}{$M_{w}$} & \multirow[b]{2}{*}{$M_{n}$} & \multirow[b]{2}{*}{ (\% rrrr) } & \multicolumn{4}{|c|}{ Activation Energy $\Delta E\left(\mathrm{~kJ} \mathrm{~mol}^{-1}\right)$} & \multirow[b]{2}{*}{ Reference } \\
\hline & & & & & $\begin{array}{l}\text { Augis- } \\
\text { Bennett }\end{array}$ & Kissinger & Takhor & Ozawa & \\
\hline s-PP\#1 & - & 165,000 & 76,200 & 77.1 & -78.6 & -94.3 & -88.6 & -76.5 & This work \\
\hline s-PP\#2 & - & 195,000 & 52,300 & 74.6 & -84.7 & -99.7 & -94.1 & -85.3 & This work \\
\hline s-PP\#3 & - & 133,000 & 37,300 & 74.6 & -108.1 & -124.0 & -118.3 & -79.7 & This work \\
\hline s-PP\#4 & - & 171,000 & 81,300 & 74.6 & -90.5 & -105.9 & -100.3 & -69.5 & This work \\
\hline s-PP\#5 & - & 165,000 & 47,000 & 75.3 & -107.3 & -123.6 & -117.9 & -89.0 & This work \\
\hline $\mathrm{s}-\mathrm{PP}(20.8 \mathrm{k})$ & - & 22,900 & 20,800 & 88 & -79.0 & -97.3 & -91.4 & - & a \\
\hline s-PP(41.7k) & - & 45,900 & 41,700 & 86 & -65.7 & -83.3 & -77.5 & - & a \\
\hline $\mathrm{s}-\mathrm{PP}(132.0 \mathrm{k})$ & - & 158,400 & 132,000 & 87 & -69.2 & -86.1 & -80.3 & - & a \\
\hline s-PP3 & 128,000 & - & - & 74.9 & -86.4 & -101.7 & -96.1 & - & $\mathrm{b}$ \\
\hline s-PP5 & 247,000 & - & - & 81.2 & -65.3 & -81.5 & -75.8 & - & $\mathrm{b}$ \\
\hline s-PP6 & 293,000 & - & - & 85.2 & -60.9 & -77.6 & -71.8 & - & $\mathrm{b}$ \\
\hline s-PP8 & 405,000 & - & - & 87.4 & -83.1 & -101.6 & -95.7 & - & $\mathrm{b}$ \\
\hline \multirow[t]{2}{*}{ s-PP9 } & 359,000 & - & - & 89.5 & -81.9 & -100.8 & -94.9 & - & b \\
\hline & & & & Average & $-81.6 \pm 14$ & $-98.3 \pm 14.4$ & $92.5 \pm 14$ & $-80.0 \pm 7$ & \\
\hline
\end{tabular}

a Evaluated from the nonisothermal crystallization data summarized in Table 5.2 of ref. 8.

${ }^{\mathrm{b}}$ Evaluated from the nonisothermal crystallization data summarized in Table II of ref. 15.

worth doing since a number of recent publications $^{16,34-36}$ have used the somewhat theoretically incomplete Kissinger method in the estimation of $\Delta E$ values for their experiments.

Values of the effective activation energy $\Delta E$ along with some important molecular characterization data of various S-PP samples are summarized in Table IX. It is apparent that the effective activation energy $\Delta E$ estimated based on the Augis-Bennett method is the lowest, with the average value of $-81.6 \pm 14.7 \mathrm{~kJ} \mathrm{~mol}^{-1}$. To verify the accuracy of the Augis-Bennett method, we also evaluated the effective activation energy $\Delta E$ based on the Ozawa kinetics results $\left(k_{o}\right.$ and $\left.n_{o}\right)$ summarized in Table VI. Since we know that the Ozawa crystallization rate constant $k_{o}$ should have the same temperature dependence as stated in eq. (11), plotting $\left(1 / n_{o}\right) \ln \left(k_{o}\right)$ versus $1 / T$ should yield $-\Delta E / R$ as the slope [cf. Fig. 9(d)]. Apparently, the $\Delta E$ values (with the average value of $-80.0 \pm 7.6 \mathrm{~kJ} \mathrm{~mol}^{-1}$ and the correlation coefficient $r^{2}$ ranging from 0.97 to 0.99 ) calculated based on the Ozawa kinetics result are very comparable to those estimated by the Augis-Bennett method.

\section{CONCLUSIONS}

The nonisothermal crystallization data of five different s-PP samples studied using DSC were an- alyzed according to three different macrokinetic models, namely, the Avrami, the Tobin, and the Ozawa models. All the three models were shown to describe the experimental data fairly well. For all of the five samples studied, the Avrami exponent $n_{a}$ was found to range from 2.4 to 5.3, while the Tobin exponent $n_{t}$ was found to range from 3.1 to 6.7. Both the Avrami and Tobin exponents, $n_{a}$ and $n_{t}$, were found to increase with the decreasing cooling rate used (i.e., $1^{\circ} \mathrm{C} \min ^{-1} \leq \phi$ $\leq 20^{\circ} \mathrm{C} \min ^{-1}$ ), which may be attributable to changes in either the growth morphology (e.g., from disclike to spherulitic to sheaflike) or the nucleation mechanism (e.g., from athermal to thermal). ${ }^{28}$ The Ozawa exponent $n_{o}$, which is essentially the same as the Avrami exponent $n_{a}$, was found to vary from 1.63 to 3.72 , remarkably comparable to the Avrami exponent $n_{a}$ observed under isothermal conditions. ${ }^{10,11}$

For each s-PP sample, all the rate parameters (i.e., $t_{0.5}^{-1}, k_{a}$, and $k_{t}$ ) suggested that s-PP crystallizes faster as the cooling rate increases. The rate of nonisothermal crystallization among different s-PP samples, as suggested by plots of reciprocal values of the time $t_{p}$ to reach the maximum crystallization rate versus the cooling rates (cf. Fig. 3 ), was shown to follow the order s-PP\#5 $>$ sPP\#3 > s-PP\#2 > s-PP\#4 > s-PP\#1. Because the syndiotacticity level of these samples are compa- 
rable, the contributing factors causing the rate of nonisothermal crystallization being in the aforementioned order were thought to be the molecular weight and its distribution and the amount of ethylene defects.

The ability of the s-PP samples to crystallize from the melt under a unit cooling rate was determined by the kinetic crystallizability parameters $G$, which were found to range from 0.93 to $1.40^{\circ} \mathrm{C} \mathrm{s}^{-1}$. Based on this parameter, the crystallization ability of all samples studied was shown to be in the following order: s-PP\#5 $>$ s-PP\#2 $>$ s-PP\#3 > s-PP\#4 $>$ s-PP\#1. Comparison with some other polymers revealed that s-PP crystallizes much slower than does nylon 6, i-PP, and nylon 66, while it crystallizes at comparable rates to PET and crystallizes faster than i-PS. Lastly, the activation energy for nonisothermal crystallization, based on the Augis-Bennett method, was found to range from -78.6 to $-108.1 \mathrm{~kJ} \mathrm{~mol}^{-1}$.

The author would like to thank Dr. Joseph Schardl of Fina Oil and Chemical Co. in Dallas, Texas, for supplying the s-PP samples, and Dr. Roger A. Phillips and his coworkers of Montell USA, Inc., in Elkton, Maryland, for performing the sample characterizations.

\section{REFERENCES}

1. Natta, G.; Pasquon, I.; Corradini, P.; Peraldo, M.; Pegoraro, M.; Zambelli, A. Rend Acad Naz Lincei 1960, 28, 539.

2. Natta, G.; Pasguon, I.; Zambelli, A. J Am Chem Soc 1962, 84, 1488.

3. Ewen, J. A.; Johns, R. L.; Razavi, A.; Ferrara, J. D. J Am Chem Soc 1988, 110, 6255.

4. Rodriguez-Arnold, J.; Bu, Z.; Cheng, S. Z. D. JMSRev Macromol Chem Phys C 1995, 35, 117.

5. Schardl, J.; Sun, L.; Kimura, S.; Sugimoto, R. J Plast Film Sheet 1996, 12, 157.

6. Sun, L.; Shamshoum, E.; DeKunder, G. In SPEANTEC Proc 1996, 1965.

7. Gownder, M. SPE-ANTEC Proc 1998, 1511.

8. Rodriguez-Arnold, J. Ph.D. Dissertation, University of Akron, 1994.

9. Rodriguez-Arnold, J.; Zhang, A.; Cheng, S. Z. D.; Lovinger, A. J.; Hsieh, E. T.; Chu, P.; Johnson, T. W.; Honnell, K. G.; Geerts, R. G.; Palackal, S. J.; Hawley, G. R.; Welch, M. B. Polymer 1994, 35, 1884.
10. Supaphol, P.; Hwu, J. J.-J.; Phillips, P. J.; Spruiell, J. E. SPE-ANTEC Proc 1997, 1759.

11. Supaphol, P.; Spruiell, J. E. J Appl Polym Sci 2000, $75,44$.

12. Miller, R. L.; Seeley, E. G. J Polym Sci Polym Phys 1982, 20, 2297.

13. Rodriguez-Arnold, J.; Bu, Z.; Cheng, S. Z. D.; Hsieh, E. T.; Johnson, T. W.; Geerts, R. G.; Palackal, S. J.; Hawley, G. R.; Welch, M. B. Polymer 1994, 35, 5194.

14. Supaphol, P.; Spruiell, J. E. Polymer 2000, 41, 1205.

15. Xu, J.; Feng, L.; Liu, Z.; Chen, L.; Deng, Y.; Cui, C.; Chen, W. J Appl Polym Sci 1999, 71, 897.

16. Supaphol, P.; Spruiell, J. E. SPE-ANTEC Proc 1999, 1834.

17. Avrami, M. J Chem Phys 1939, 7, 1103; 1940, 8, $212 ; 1941,9,177$.

18. Tobin, M. C. J Polym Sci Polym Phys 1974, 12, 399; 1976, 14, 2253; 1977, 15, 2269.

19. Ozawa, T. Polymer 1971, 12, 150.

20. Ziabicki, A. Appl Polym Symp 1967, 6, 1.

21. Ziabicki, A. Polymetry 1967, 12, 405.

22. Ziabicki, A. In Fundamentals of Fiber Spinning; Wiley: New York, 1976; pp 112-114.

23. Augis, J. A.; Bennett, J. E. J Thermal Anal 1978, $13,283$.

24. Kissinger, H. E. J Res Nat Bur Stand 1956, 57, 217.

25. Takhor, R. L. In Advances in Nucleation and Crystallization of Glasses; American Ceramics Society: Columbus, 1971; pp 166-172.

26. Supaphol, P.; Spruiell, J. E. J Appl Polym Sci 2000, $75,337$.

27. Supaphol, P. J Appl Polym Sci, accepted for publication.

28. Wunderlich, B. In Macromolecular Physics; Academic: New York, 1976; Vol. 2, p 147.

29. Evans, U. R. Trans Faraday Soc 1945, 41, 365.

30. Jeziorny, A. Polymer 1978, 19, 1142.

31. Yinnon, H.; Uhlmann, D. R. J Non-Cryst Solids 1983, 54, 253.

32. Kolmogoroff, A. N. Izvest Akad Nauk USSR Ser Math 1937, 1, 355.

33. Johnson, W. A.; Mehl, K. F. Trans Am Inst Mining Met Eng 1939, 135, 416.

34. Liu, T.; Mo, Z.; Wang, S.; Zhang, H. Polym Eng Sci 1997, 37, 568.

35. Liu, T.; Mo, Z.; Zhang, H. J Appl Polym Sci 1998, $67,815$.

36. Liu, S.; Yu, Y.; Cui, Y.; Zhang, H.; Mo, Z. J Appl Polym Sci 1998, 70, 2371. 